\title{
Particulate exhaust analysis from internal combustion engines
}

\begin{abstract}
Today the world is worried over the particulate emission from various forms of internal combustion engines. The present work is an attempt to understand the constituents of the particulate emission and its possible use. The particulate exhaust matter containing carbonaceous soot produced from the combustion of fuel containing hydrocarbons shows the presence of significant amount of carbon Nanomaterials. Hydrocarbons are the most widespread precursors among carbon sources employed in the production of carbon nanotubes (CNTs) and carbon nanoparticles (CNPs). Carbon nanotubes find application in fuel cells providing improved performance. The soot particles collected from the internal combustion diesel engines are cleaned, powdered and analyzed by various techniques. The CNPs are characterized by Field Emission Scanning Electron Microscopy (FESEM), X-Ray Powder Diffraction (XRD), Energy Dispersive X ray diffraction (EDS), Raman Spectroscopy, Photoluminescence spectroscopy (PL), Power spectrum and CIE plot. X Ray Diffraction and Raman spectroscopic analysis show the presence of carbon nanotubes in the amorphous materials.
\end{abstract}

Keywords: hydrocarbons, carbon nanotubes, diesel engines, CIE plot, EDX, raman spectroscopy
Volume I Issue 3 - 2017

\author{
Swapna MS,' Arsha RC,' Dani Dileep, \\ Rageena Joseph, ${ }^{2}$ Sankararaman $S^{\prime}$ \\ 'Department of Optoelectronics, Nanoscience and \\ Nanotechnology, University of Kerala, India \\ ${ }^{2}$ Department of Physics, Newman College, India
}

\begin{abstract}
Correspondence: Sankararaman S, Department of Optoelectronics and Department of Nanoscience and Nanotechnology, University of Kerala, Kariavattom Campus, Trivandrum, Kerala, India- 69558I, Tel 9447421844, Email drssraman@gmail.com
\end{abstract}

Received: November 18, 2017 | Published: December 18, 2017
Abbreviations: CNTs, carbon nanotubes; CNPs, carbon nanoparticles; FESEM, field emission scanning electron microscopy; XRD, X-Ray powder diffraction; EDS, energy dispersive X Ray diffraction; PL, photoluminescence spectroscopy; ICEs, internal combustion engines

\section{Introduction}

Nanoscience and technology have grown explosively in the las decades, because of various synthesis procedures and characterization techniques. ${ }^{1}$ From the nineteenth century, carbon nanoparticles are one among the blooming fields of research and have been in constant limelight since then, due to its unique physical and chemical properties, making it a whole host of applications ranging from clean energy to nanoscale electronics. ${ }^{2-9}$ The carbon is the sixth most abundant available element in the universe, which is a non-metallic element commonly obtained from coal deposits. The toxicity level to humans is very less for the pure carbon, which makes its application in almost every field of science and technology. The carbon exists in a many allotropic forms, among them graphite, diamond, and amorphous carbon are naturally occurring. Coal, soot, carbidederived carbon and other impure forms of carbon also come under the terminology amorphous carbon. They are not truly amorphous, but rather polycrystalline materials within an amorphous carbon matrix.

Hydrocarbons are organic compounds consisting of carbon and hydrogen elements only. At present lot of hydrocarbons are used as precursors in several methods of nanoparticles preparation. Simplest form of hydrocarbons, i.e. saturated hydrocarbons contains only single bonds. The unsaturated forms of them have double or triple bonds in their structure and aromatic hydrocarbons have at least one aromatic ring. Diesel, Kerosene, paraffin wax etc. are the most commonly used hydrocarbon sources for the production of carbon nanoparticles. ${ }^{10,11}$
Today diesel engines are used worldwide for power generation, farming, manufacturing, construction and very importantly in transportation. The saturated and aromatic hydrocarbons in diesel take part in the combustion process. In an unsteady mode and environment, the diesel engine combustion takes place at very high temperatures and pressures. ${ }^{12}$ The common diesel fuel is chemically represented as $\mathrm{C}_{12} \mathrm{H}_{23}$ (ranges from $\mathrm{C}_{10} \mathrm{H}_{20}-\mathrm{C}_{15} \mathrm{H}_{28}$ ). The products of the incomplete combustion of hydrocarbons, called soot particles are the actual source of nanoparticles synthesis. The incomplete combustion depends on the environment of burning. Some environments don't enable enough oxygen to get into the gas mixture to drive complete combustion and the reactions can easily leave a lot of sooty emissions.

Combustion also known as burning is the basic chemical process of releasing energy from a fuel and air mixture. This combustion method belongs to the class of bottom-up method of nanoparticles synthesis, where we require a combustion chamber of high temperature and pressure. Since the diesel engine provides high temperature and pressure essential for the breakdown of hydrocarbons we have made use of the internal combustion engine for the synthesis of carbonaceous soot particles. In the present work, we try to investigate the various constituents in the particulate matter exhaust from the internal combustion engines (ICEs). In order to understand the presence of various allotropic forms of carbon in the sample synthesized the samples are subjected to various characterizations by FESEM, EDS, XRD, PL, and Raman spectroscopy.

\section{Experimental methods}

For the effective use of the particulate matter emitted by ICEs, proper analysis and understanding of its constituents are essential. Internal combustion engines are seen mostly in transportation. In an ICE the combustion of fuel occurs in the combustion chamber 
resulting in the formation of particulate matter (Block diagram of internal combustion engine is shown in Figure1).

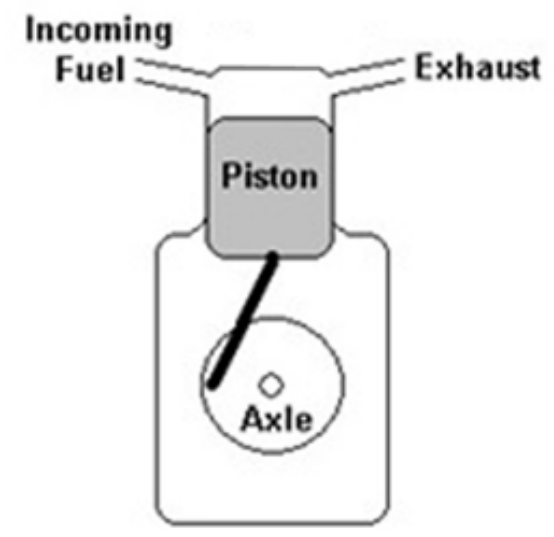

Figure I Block diagram of internal combustion engine.

The particulate exhaust from the ICE are collected and purified by liquid phase oxidation method, in which, the sample is mixed with sulphuric acid and nitric acid in the ratio 1:3, ultrasonicated using Scientech SE-366 for 30 minutes, filtered with Whatman Filter paper 41 and washed with distilled water three times. Then it is quenched with ice-cooled water and base neutralized with sodium hydroxide. ${ }^{13}$ Then the sample is again washed with distilled water four times and filtered with Whatman Filter paper 42.

The morphological and elemental analysis of the exhaust diesel soot is done by Nova Nano FESEM and JEOL JEM-2100 TEM. In order to understand the crystallinity of the soot particles, XRD measurement is carried out using a Bruker D8 Advanced Diffractometer with $\mathrm{CuK} \alpha$ radiation $(\lambda=1.5406 \AA)$. The Raman Spectrum of the carbonaceous soot is recorded using Lab Ram Micro-Raman Spectrometer. Photo luminescent Spectrum of the sample is recorded using Horiba Fluoromax.

\section{Results and discussion}

The particulate exhaust particles synthesized by the internal combustion engines are subjected to morphological and structural analysis. The FESEM and HR-TEM images of the sample are shown in Figure 2. The FESEM image reveals the presence of agglomerated carbon nanoparticles of size between 30 and $40 \mathrm{~nm}$, whereas the HRTEM image shows carbon nanotubes and graphene sheets. From the EDX spectrum of the soot particle given in Figure 3, it can be seen that the emission contains sulphur, sodium, potassium and chlorine in addition to carbon and oxygen. From Figure 3b, it can be seen that the purification has removed the impurities and elements other than carbon and oxygen.

The XRD spectrum of the soot sample shown in Figure 4 exhibit a strong and broadened $\pi$ band around $25.16^{\circ}$ which corresponds to $\mathrm{E}_{2 \mathrm{~g}}$ mode of graphite due to $\mathrm{sp}^{2}$ bonded carbon atoms and the ordered CNTs in the sample. This indicates that the CNPS formed are composed of crystalline graphitic carbon. ${ }^{14}$ The peak around $42.65^{\circ}$ from (100) plane is due the hexagonal lattice of multiwalled CNT. This is in agreement with the values reported in literature. ${ }^{15-21}$ From the XRD spectra one can understand that the particulate diesel soot contains CNTs.
Raman spectrum is a proven tool for structural evaluation of materials. The nanostructures are formed by the addition of hexagonal and pentagonal rings as building blocks. The temperature in the internal combustion engine plays a significant role in the formation of carbon nanotubes and graphene layers. It is well understood that a CNT exhibit two characteristic bands in the Raman spectrum and is also evident from Figure 5. A stretching $\mathrm{G}$ mode or Graphitic mode around $1600 \mathrm{~cm}^{-1}$ and a defect band or D mode around $1350 \mathrm{~cm}^{-1}$. The Raman spectrum of highly ordered graphite shows a first order features in the region 1100-1700 $\mathrm{cm}^{-1}$ and second order features between 2400 and $3300 \mathrm{~cm}^{-1}$. In the sample formed from the internal combustion engine we could observe all these bands. The $\mathrm{G}$ band corresponds to the first order scattering of the $\mathrm{E}_{2 \mathrm{~g}}$ mode of $\mathrm{sp}^{2}$ carbon. ${ }^{22,23}$ The $\mathrm{D}$ and $\mathrm{G}$ bands in the Raman spectrum obtained from the diesel soot are observed at $1373 \mathrm{~cm}^{-1}$ and $1602 \mathrm{~cm}^{-1}$ respectively. The higher order modes are also observed at $1811 \mathrm{~cm}^{-1}$ and $2204 \mathrm{~cm}^{-1}$ confirming the formation of CNTs in the diesel soot.
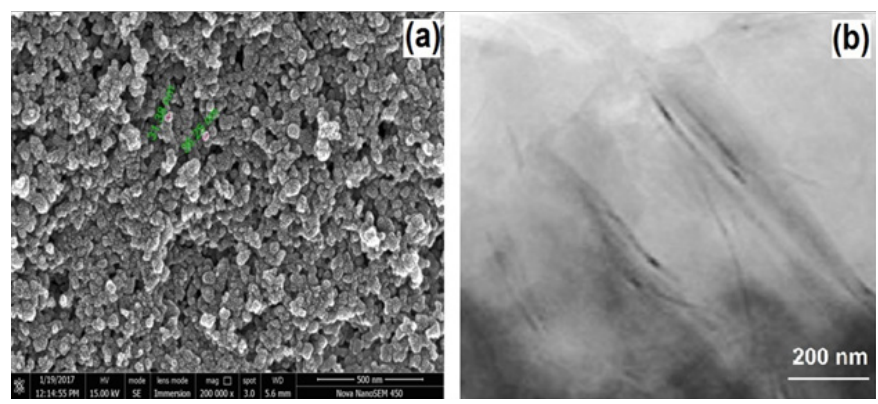

Figure 2 FESEM images of soot particles.
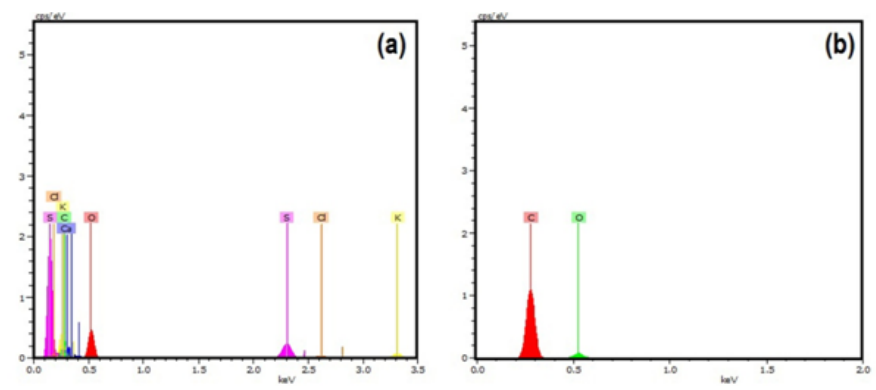

Figure 3 EDX Spectrum of diesel soot

A) Before purification. B) After purification

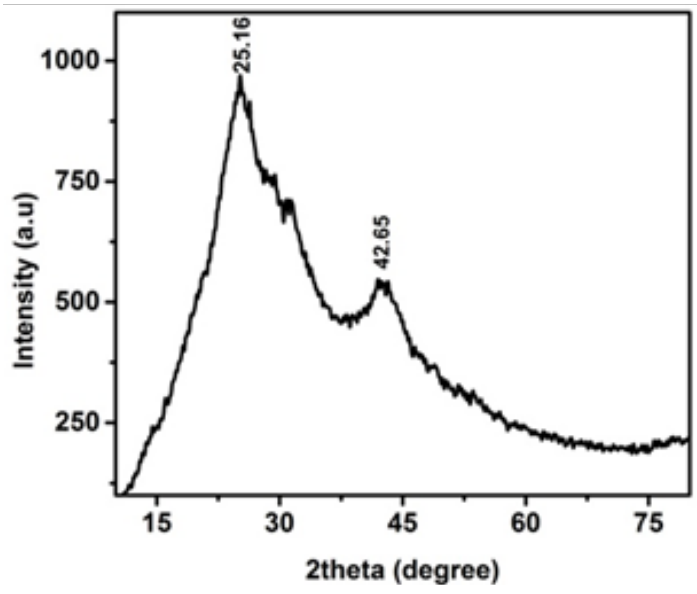

Figure 4 XRD pattern of diesel soot. 


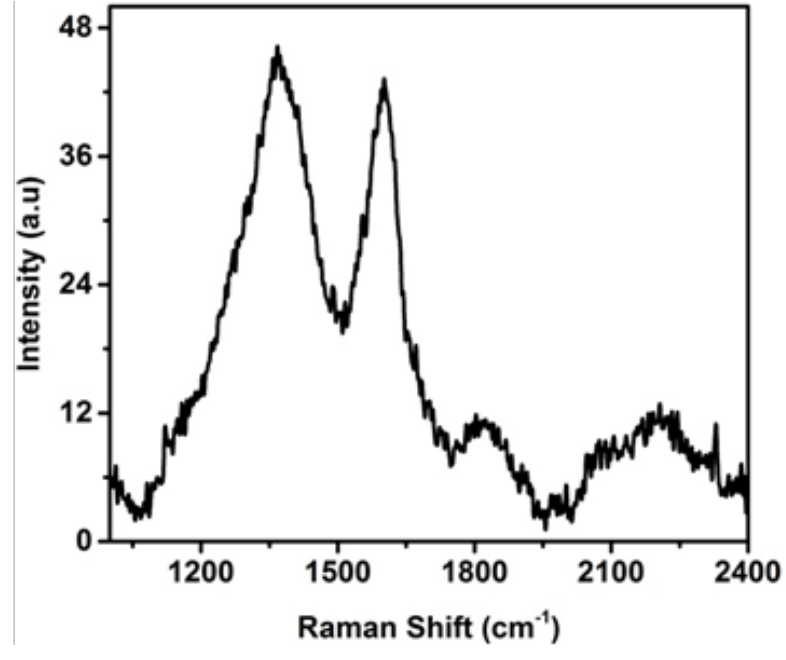

Figure 5 Raman Spectrum of diesel soot.

The fluorescent properties are analyzed by Photoluminescence spectroscopy, power spectrum and CIE plot. The emission spectra is recorded at an excitation wavelength of $430 \mathrm{~nm}$.The PL spectrum along with the power spectrum and CIE plot is given in Figure 6.
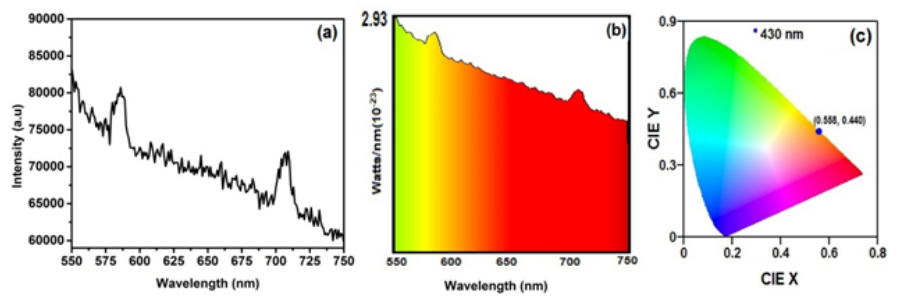

Figure 6
a) PL Spectrum
b) Power spectrum
c) CIE plot of diesel soot.

The Photo luminescent spectrum of the sample shows the characteristic peaks at $586 \mathrm{~cm}^{-1}$ and $707 \mathrm{~cm}^{-1}$ for an excitation at 430 $\mathrm{nm}$. The quantitative links between the emitted wavelengths and the human color perception can be depicted using CIE coordinates. The emission from the sample for the excitation $430 \mathrm{~nm}$ is pictorially shown in the CIE XYZ color space of the chromaticity diagram Figure $6 \mathrm{c}$. The chromaticity coordinates are obtained as $(0.558,0.440)$ with emission in the orange red region. The power spectrum Figure $6 \mathrm{~b}$ and the CIE plot suggest the possible use of the diesel soot for photonic applications.

\section{Conclusion}

Today world is worried about the carbon emission and the particulate matter (soot) from internal combustion engines (ICEs). The present work suggests the effective utilization and application of the hazardous diesel soot. The structural and morphological analysis of the particulate matter from the ICEs reveals the presence of various constituents of carbon. From the study, we can see that the internal combustion engines are capable of producing good quality CNTs. Hence, the particulate matter rich in carbon can be used for potential applications in fuel cell, carbon nano capacitors etc. The study is highly significant in the context of pollution and search for low-cost material for photonics and electronics applications and thereby turning the hazardous, futile material into a fruitful material. We have also reported the use of camphor soot as blue light emitter and investigated its UV- protection action in leaves. ${ }^{9,23}$

\section{Acknowledgments}

None.

\section{Conflicts of interest}

There is no conflict of interest.

\section{References}

1. Bang JH, Suslick KS. Applications of Ultrasound to the Synthesis of Nanostructured Materials. Adv Mater. 2010;22(10):1039-1059.

2. Anu N Mohan, Manoj B. Synthesis and Characterization of Carbon Nanospheres from Hydrocarbon Soot. Int $J$ Electrochem Sci. 2012;7(2012): 9537-9549.

3. Kumar M, Ando Y. Single-wall and multi-wall carbon nanotubes from camphor-a botanical hydrocarbon. Diamond and Related Materials. 2003;12(10-11):1845-1850.

4. Ungár T, Gubicza J, Gabor R, et al. Microstructure of carbon blacks determined by X-ray diffraction profile analysis. Carbon. 2002;40(6):929-937.

5. Swapna MS, Sankararaman S. Carbon Nanonecklaces with Carbon Nanotubes and Carbon Dots. International Journal of Materials Science. 2017;12(4):541-548.

6. Swapna MS, Sankararaman S. Fractal analysis a surrogate technique for material characterization. Nanosystems: Physics, Chemistry, Mathematics. 2017;8(6):0-6

7. Swapna MS, Sankararaman S. Investigation of graphene oxide from diesel soot. J Mater Sci Nanotechnol. 2017;5(1):1-6.

8. Swapna MS, Pooja VM, Anamika SA, et al. Synthesis and Characterization of Carbon Nano Kajal. JOJ Material Sci. 2017;1(4): 555566.

9. Swapna MS, Beryl C, Reshma SS, et al. Ultraviolet Protection Action of Carbon Nanoparticles in Leaves. Bio Nano Sci. 2017;7(4):583-587.

10. Santana DWEA, Sepulveda MP, Barbiera PJS. Spectrophotometric determination of the ASTM color of diesel oil. J Fuel. 2007;86(5-6): 911-914.

11. Al-Ghouti M, Al-Degs Y, Mustafa F. Determination of hydrogen content, gross heat of combustion and net heat of combustion of diesel fuel using FTIR spectroscopy and multivariate calibration. Fuel. 2010;89:193-201.

12. Heywood JB. Internal Combustion Engine Fundamentals. McGraw-Hill, New York, USA, 1998.

13. Hussain S, Jha P, Chouksey A, et al. Spectroscopic investigation of Modified Single Wall Carbon Nanotube (SWCNT). J Mod Phys. 2011;2(6):538-243.

14. Manoj B. Characterization of Nano-Crystalline Carbon from Camphor and Diesel by X-ray Diffraction Technique. Asian J Chem. 2014;26(15):4553-4556.

15. Manoj B, Kunjomana AG. Structural Characterization of selected Indian coals by X-ray diffraction and spectroscopic techniques. Trends in applied sciences research. 2012;7(6):434-444.

16. Manoj B, Kunjomana AG. FT-Raman Spectroscopic Study of Indian Bituminous and Sub-bituminous Coal. Asian J Mater Sci. 2010;2(4):204-210 
17. Sonibare OO, Haeger T, Foley SF. Structural characterization of Nigerian coals by X- ray diffraction, Raman and FTIR spectroscopy. Energy. 2010;35(12):5347-5353.

18. Malek Abbaslou RM, Jafar S, Ajay KD. Effect of nanotubes pore size on the catalytic performance of iron catalysts supported on carbon nanotube for Fisher-Tropsch synthesis. Appl Catal A: Gen. 2010;379(1-2):129-134.

19. Dikio ED. Morphological characterization of soot from the atmospheric combustion of kerosene. E J Chem. 2011;8(3):1068-1073.

20. Shooto DN, Dikio ED. Synthesis and characterization of diesel, kerosene and candle wax soot's. Int J Electrochem Sci. 2012;7(2012): 4335-4344.
21. Kumar M, Kichambare PD, Sharon M, et al. Synthesis of conducting fibers, nanotubes, and thin films of carbon from commercial kerosene. Mat Res Bulletin. 1999;34(5):791-801.

22. Osswald S, Flahaut E, Ye H. Material science and engineering department and AJ Drexel nanotechnology institute, Elsevier, Netherlands, 2004.

23. Swapna MS, Saritha Devi HV, Sankararaman S. Camphor soot: A Tunable Light Emitter. Applied Physics A. 2018;124:50. 